\title{
Experimental and theoretical investigations of methyl formate oxidation including hot beta-scission
}

\section{Minwegen, Heiko}

2019

Minwegen , H, Döntgen , M , Hemken , C , Büttgen , R D , Leonhard , K \& Heufer , K A 2019 , ' Experimental and theoretical investigations of methyl formate oxidation including hot beta-scission ' , Proceedings of the Combustion Institute , vol. 37 , no. 1 , pp. 307-314 . https://doi.org/10.1016/j.proc

http://hdl.handle.net/10138/325134

https://doi.org/10.1016/j.proci.2018.06.111

cc_by_nc_nd

acceptedVersion

Downloaded from Helda, University of Helsinki institutional repository.

This is an electronic reprint of the original article.

This reprint may differ from the original in pagination and typographic detail.

Please cite the original version. 


\title{
Experimental and theoretical investigations of methyl formate oxidation including hot $\beta$-scission
}

\author{
Heiko Minwegen ${ }^{\mathrm{a}, *}$, Malte Döntgen ${ }^{\mathrm{b}, \mathrm{d}}$, Christian Hemken ${ }^{\mathrm{a}}$, Rene Daniel \\ Büttgen $^{\mathrm{a}}$, Kai Leonhard ${ }^{\mathrm{b}, \mathrm{c}}$, Karl Alexander Heufer ${ }^{\mathrm{a}}$ \\ ${ }^{a}$ Physico-Chemical Fundamentals of Combustion, RWTH Aachen University, Germany \\ ${ }^{b}$ Chair of Technical Thermodynamics, RWTH Aachen University, Germany \\ ${ }^{c}$ AICES Gratute School, RWTH Aachen University, Aachen, Germany \\ ${ }^{d}$ Molecular Science, Department of Chemistry, University of Helsinki, FI-00560 Helsinki, \\ Finland
}

\begin{abstract}
Recently the possibility of hot $\beta$-scission pathways gained attention. These reactions give a shortcut during the important fuel consumption phase in combustion processes leading from $\mathrm{H}$-atom abstraction directly to the $\beta$ scission products without fuel radical thermalization. Methyl formate (MF) was shown to be prone to hot $\beta$-scission due to a low $\beta$-scission barrier height. Furthermore, MF as smallest methyl ester can be considered as biodiesel surrogate and it is an important intermediate product during combustion of various ethers. In this work a predominantly ab-initio derived detailed kinetic model of MF combustion is developed including hot $\beta$-scission pathways and compared to a sophisticated literature model based on classical estimation methods. For this, new stoichiometric MF in air ignition delay time measurements in a shock tube and a rapid compression machine over a wide temperature range $(790 \mathrm{~K}-1250 \mathrm{~K})$ and pressures of 10,20 and
\end{abstract}

\footnotetext{
*Corresponding author:

Email address: minwegen@pcfc.rwth-aachen.de (Heiko Minwegen)
} 
40 bar served as validation targets. The experimental ignition delay times (IDT) show Arrhenius type behaviour in both facilities at all conditions. The newly developed quantum-based model catches the pressure dependency and low-temperature reactivity well although overpredicting the IDT at higher temperatures. It was found that hot $\beta$-scission is the major depletion pathway of formate group-centered MF radicals. This, however, does not change the overall reactivity of MF combustion due to the low stability of the alkyl peroxide $\left(\mathrm{RO}_{2}\right)$ at the formate group. For species with competing thermal $\beta$-scission and $\mathrm{RO}_{2}$ formation, however, hot $\beta$-scission may have a significant impact.

Keywords: methyl formate, hot beta scissions, ab-initio, kinetic modelling, Ignition Delay Times

\section{Introduction}

Methyl formate (MF) is considered as biodiesel surrogate [1] and can be observed as combustion intermediate in dimethyl ether (DME) [2] and dimethoxymethane (DMM) [3, 4] combustion. However, detailed chemical kinetic modeling of MF has been of minor interest so far compared to e.g. DME. The increasing interest in oxymethylene ethers as potential fuels [5] or diesel additives [6], however, makes it inevitable to revisit available kinetic models for MF and to discuss the underlying chemistry. Moreover, the recent work by Döntgen et al. $[7,8]$ on the kinetics of chemically activated MF radicals, so-called hot $\beta$-scission, sheds new light on the conclusions of the work of Dooley et al. [9] stating a fundamental lack of understanding of the molecular decomposition process of methyl formate. In the present work, we 
propose a detailed chemical kinetic model for MF which is using the most recent available quantum chemical predicitions. With this model, we aim at facilitating fundamental understanding of the role of hot $\beta$-scission during MF combustion and to figure out which elementary reactions require further investigation.

So far, to the best of our knowledge, only few distinct MF kinetic models have been proposed: In 2010, Dooley et al. [9] proposed a sophisticated MF kinetic model mainly using analogies to other compounds. For validation, variable-pressure flow reactor, shock tube, and laminar burning velocity experiments have been conducted. Dooley et al. [9] identified high uncertainties in the rate constants for MF elimination reactions. Later, Tan et al. [10, 11] used high-level quantum chemical methods to predict MF hydrogen abstraction kinetics, tackling exactly those highly uncertain reactions identified by Dooley et al. [9]. In 2011, West et al. [12] proposed a kinetic model building on estimations from the RMG software package [13] updated with high level QCISD(T) // B3LYP predictions for MF and MF radical reactions. West et al. [12] compared their newly generated kinetic model to two basemechanisms not explicitly created for MF, and to the kinetic model proposed by Dooley et al. [9]. As key conclusion, West et al. [12] stated that measured speciation data cannot be reproduced accurately by any of the investigated MF kinetic models.

Recently, Alzueta et al. [14] and Marrodán et al. [15] measured MF oxidation speciation data in an isothermal tubular quartz flow reactor, the results of which were compared to simulated speciation data using the Dooley et al. [9] kinetic model. Alzueta et al. [14] found that the results are very 
sensitive to the activation energy of the unimolecular decomposition of MF to $\mathrm{CH}_{3} \mathrm{OH}+\mathrm{CO}$. This observation agrees with the previously mentioned uncertainties of the MF elimination reaction in the Dooley et al. [9] kinetic model. Also Metcalfe et al. [16] underlined these results along with a previous work from Francisco [17] in their theoretical investigations of MF decomposition reactions, based on different computational compound methods. In the studies $[16,17]$ the $\mathrm{MF}$ decomposition to $\mathrm{CH}_{3} \mathrm{OH}+\mathrm{CO}$ was identified as most favored, related to the calculated reaction barriers. Later, Ren et al. [18, 19] measured species time histories of MF pyrolysis in the shock tube opening the opportunity to derive experimental reaction rate constants for this decomposition channel. Their results agree to the estimated rate constant provided by Dooley et al. [9].

In order to build a MF kinetic model mostly consisting of quantum chemical predictions, the hydrogen abstraction rate constants of Tan et al. [10, 11], as well as the unimolecular MF radical kinetics predictions of Tan et al. [20] will be taken into account. The latter MF radical kinetics predictions were obtained via RRKM/ME simulations, using high-level quantum chemical data as input [20]. Building on the above studies of the Carter group in Princeton [10, 11, 20], Döntgen et al. [7, 8] investigated the direct dissociation of freshly formed rovibrationally excited MF radicals. These hot $\beta$ scission reaction pathways were found to dominate over a wide temperatureand pressure-range and even at engine relevant conditions.

Similarly, hot $\beta$-scissions were also previously considered in different kinetic modeling studies. Two recent companion studies on non-Boltzmann distributed thermally activated $\mathrm{RO}_{2}$ chemistry and in particular ketohy- 
droperoxide decomposition kinetics subsequent to propyl radical formation are thematized from Burke et al.[21] and Goldsmith et al.[22], respectively. They presented a methodology for the consideration of non-Boltzmann distributed reactants in kinetic modeling enabling the suggestion to include hot intermediates for the interpretation of low pressure measurement data with detailed kinetic models. Furthermore, Labbe et al. [23, 24] investigated prompt dissociation pathways of formyl radical (HCO) subsequent to H-atom abstraction from formaldehyde and the interaction with other fuels in several literature kinetic models. They found in particular that simulational results of flame propagation velocities including these prompt dissociation pathways were promoted by around $10-15 \%$. Still, it remains unclear if the dominant role of hot $\beta$-scission in MF radical chemistry outlasts at the macroscopic scale, and if yes, how it manifests.

With the uncertainties stated by Dooley et al. [9], the discrepancies stated by West et al. [12], and the novel chemistry proposed by Döntgen et al. [7, 8] in mind, a detailed chemical kinetic modeling study of MF will be conducted in the present work. Using quantum chemical information from previous studies and adding new calculations for MF low-temperature oxidation chemistry will yield a kinetic sub-mechanism mostly based on ab-initio predictions. This new kinetic model will be validated against new shock tube (ST) and rapid compression machine (RCM) measurements at 10, 20, and 40 bar and stoichiometric conditions. With this MF kinetic model, we aim for elucidating the role of hot $\beta$-scission during engine-relevant MF combustion and we will use it to identify open questions in the kinetic modeling of MF. 


\section{Experimental Facilities}

The rapid compression machine (RCM) facility at RWTH Aachen University described in detail in [25] is equipped with a creviced piston to suppress roll up vortex and a flexible end wall for variation of the compression ratio. The reaction chamber, the manifold lines, and the mixing vessels can be electrically heated to avoid the condensation of fuels at the walls. Mixtures are prepared manometrically using two static pressure sensors (STS $1^{\text {st }}$ 0-500 mbar, STS $1^{\text {st }} 0-5$ bar). The dynamic pressure change in the reaction chamber during the measurement is recorded with the aid of a thermal shock resistant Kistler $6125 \mathrm{C}$ sensor. The adiabatic compression and expansion routine of Gaseq [26] is used for calculation of the end of compression (EOC) temperature. The reactive conditions are repeated at least once to check for

the repeatability of the resulting IDT. The time interval between the end of compression pressure and the steep pressure rise due to ignition defines the IDT in the RCM for this work. The uncertainties in the end of compression temperature and pressure measurements were determined to $\pm 5 \mathrm{~K}$ and \pm 0.2 bar respectively. The procedure of uncertainty estimation has been described in detail by Ramalingam et al. [27]. The variation in the RCM IDT measurements for MF is determined to $\pm 15 \%$.

The shock tube at RWTH Aachen University has been described before in $[28,29]$. Briefly, the stainless steel shock tube with an inner diameter of $6.35 \mathrm{~cm}$ contains a $4.1 \mathrm{~m}$ long measuring section, driven by a $3 \mathrm{~m}$ long driver section. A double diaphragm chamber separates the two parts to control the execution of the experiments while using two pre-scored aluminium diaphragms. Close to the end wall of the driven section 5 PCB $113 \mathrm{~B} 22$ dy- 
namic pressure sensors are used to record the pressure and shock velocity, respectively. The fuel air mixtures are prepared in a teflon coated mixing vessel where the pressures are monitored again with two static pressure sensors (STS $1^{\text {st }} 0-500$ mbar, STS $1^{\text {st }} 0-10$ bar). The mixing vessel and the driven section along with the diaphragm chamber are electrically heated. With the initial conditions of pressure, temperature, mixture composition and the measured shock velocity the reflected shock conditions were calculated in Cantera [30] including the numerical routines from the shock and detonation toolbox [31]. In the shock tube measurements the IDT time interval is defined between the pressure rise of the reflected shock and the steep ignition pressure rise, measured with the pressure transducer closest to the endwall $(9 \mathrm{~mm})$. The uncertainty to be expected in the measured IDT based on a detailed comprehensive study in different shock tube facilities [32] is within $20 \%$. Uncertainties in the determination of pressures and temperatures for the MF experiments are of $1.5 \%$ and $0.6 \%$ respectively. A detailed description of the uncertainty analysis is provided in previous studies [28, 29].

For both the facilities high purity grade gases $(\geqslant 99.999 \%)$ of $\mathrm{O}_{2}, \mathrm{~N}_{2}$ and Ar and anhydrous, 99 \% MF obtained from Sigma Aldrich were used for preparing the mixtures. A table of all experimental results can be found in the Supplementary Material.

\section{Computational methods}

\subsection{Methyl formate low-temperature oxidation chemistry}

In the literature, controverse discussion about whether MF exhibits a negative temperature coefficient (NTC) regime and how much $\mathrm{RO}_{2}$ chemistry 
influences the combustion behavior of MF can be found [33-35]. Being able to settle this discussion requires a detailed chemical kinetic model with definite rate constants for $\mathrm{RO}_{2}$ chemistry of MF. Since no ab-initio study on $\mathrm{MF} \mathrm{RO}_{2}$ chemisty is available, we predict the temperature- and pressure-dependent rate constants for the first $\mathrm{O}_{2}$ addition, $\mathrm{RO}_{2}$ isomerization and dissociation, and $\mathrm{QOOH}$ dissociation in the present work.

The molecular structures, harmonic frequencies, hindered rotor profiles, and the $\mathrm{MF} \mathrm{RO}_{2} / \mathrm{QOOH}$ potential energy surface (PES) are calculated at the $\operatorname{CCSD}(\mathrm{T}) / \mathrm{CBS} / /$ B3LYP/6-311++G(d,p) level of theory, using the Gaussian software package [36]. The complete basis set (CBS) limits are calculated based on $E_{\mathrm{CBS}}=E_{X}-a X^{-3}$ [37], with $X=2,3$ for the augcc-pVXZ basis sets. Rice-Ramsperger-Kassel-Marcus (RRKM) / Master Equation (ME) simulations for the reactions on the $\mathrm{RO}_{2}$ / QOOH PES are carried out using the MESS software package [38]. The MF radical $+\mathrm{O}_{2}$ kinetics are predicted using the VRC-TST approach with the relative translation of the two fragments modeled as analogy to DME radical $+\mathrm{O}_{2}$ [39]. Collisional energy transfer is modeled with the Lennard-Jones (LJ) collision frequency model and a single-exponential $\left\langle\Delta E_{\text {down }}\right\rangle$ model [40], using the parameters proposed by Tan et al. [20] for the MF radical reaction system. The temperature-dependence of the single-exponential $\left\langle\Delta E_{\mathrm{down}}\right\rangle$ model is described as $\left\langle\Delta E_{\text {down }}\right\rangle=200 \mathrm{~cm}^{-1} \cdot\left(T / T_{0}\right)^{0.85}$.

\subsection{Unimolecular methyl formate radical chemistry}

The isomerization and $\beta$-scission kinetics of MF radicals are calculated from RRKM/ME simulations based on the CCSD(T)/CBS // CCSD(T)/ccpVTZ data of Tan et al. [20], using the MESS software packge [38]. The CBS 
limits are calculated using the aforementioned extrapolation scheme and the cc-pVTZ and cc-pVQZ basis sets. Collisional energy transfer is modeled using the LJ collision frequency model with the LJ parameters proposed by Tan et al. [20] and the exact same single-exponential $\left\langle\Delta E_{\text {down }}\right\rangle$ model as described above. For further computational details, please refer to [7, 20].

As mentioned in the introductory part of this work, Döntgen et al. $[7,8]$ recently proposed that MF radicals formed via hydrogen abstraction could directly dissociate via so-called hot $\beta$-scission reactions. In these reactions, the excess energy released from hydrogen abstraction causes rovibrational excitation of the MF radicals, enhancing their dissociation rate constants significantly. The MF radical hot $\beta$-scission branching ratios are obtained from applying a non-Boltzmann energy-distribution to the energy-dependent branching ratios calculated from the ME simulations. The non-Boltzmann energy-distributions of the MF radicals in turn are calculated as the normalized product of Boltzmann energy-distributed hydrogen abstraction reactants and the effective microscopic hydrogen abstraction rate constants obtained via inverse Laplace transformation of the respective high-pressure rate constants, as described by Döntgen et al. [7]. High-temperature extrapolations of the hot $\beta$-scission branching ratios are required to obtain information throughout the whole temperature regime since the ME cannot be solved distinctly above certain temperatures, as described by Döntgen et al. [8].

\section{Model Development}

The development of the kinetic sub-mechanism for MF combustion in this work is driven by the support of quantum chemical computations containing 
low- and high-temperature reaction pathways. Low temperature chemistry $\left(\mathrm{RO}_{2}\right)$ is described by 37 reactions out of a total of 86 reactions for 9 fuel related species. The calculation details to the according reaction rate constants and thermochemistry calculations are described in detail in section 3. The Hatom abstraction reactions forming the fuel radicals via $\mathrm{O}, \mathrm{OH}, \mathrm{CH}_{3}, \mathrm{H}$ and $\mathrm{HO}_{2}$ are implemented considering thermalized and hot $\beta$-scission pathways. Pressure dependencies were also determined for the radical decompostion pathways. For both, the $\mathrm{H}$-atom abstraction reactions and the radical decompostion the underlying results are taken from the quantum calculations provided by Tan et al. $[10,11,20]$.

$\mathrm{H}$-atom abstraction by $\mathrm{CH}_{3} \mathrm{O}_{2}$ and $\mathrm{OCHO}$ radicals from the fuel are considered to be analogous to abstractions by $\mathrm{HO}_{2}$. The rate constants for the unimolecular decomposition of MF were taken from Dooley et al. [9], since the decomposition to $\mathrm{CH}_{3} \mathrm{OH}+\mathrm{CO}$ is in agreement with the measurements from Ren et al. [19]. Whereas the predicted rate constants from Metcalfe et al. [16] were shown as too low in the relevant temperature regime [19]. Also, the $\mathrm{H}$-atom abstraction by $\mathrm{CH}_{3} \mathrm{O}, \mathrm{HCO}, \mathrm{O}_{2}$ and the fuel radicals of methyl formate as well as the thermochemistry for the fuel were taken from Dooley et al. [9]. It has to be noted that the reaction rate constant for the $\mathrm{H}$-atom abstraction by $\mathrm{CH}_{3} \mathrm{O}$ leading to the formation of the MF radical at the formate group was estimated according to the bond dissociation energies. The rate coefficient of this reaction was lowered in this study by a factor of 10 since this reaction led to a significant overprediction of the reactivity at lower temperatures. The new sub-mechanism was implemented in a $\mathrm{C}_{0}-\mathrm{C}_{2}$ base mechanism taken from the AramcoMech 2.0 [41]. Missing transport 
data were generated with the estimation routines implemented in RMG [13]. The complete kinetic model is provided in the Supplemental Material in CHEMKIN II format.

\section{5. $\mathrm{RO}_{2}$ chemistry}

The potential energy surfaces (PESs) of the two RO2 adducts stemming from the methyl-centered and the formate-centered MF radicals are shown in Figures 1 and 2, respectively.

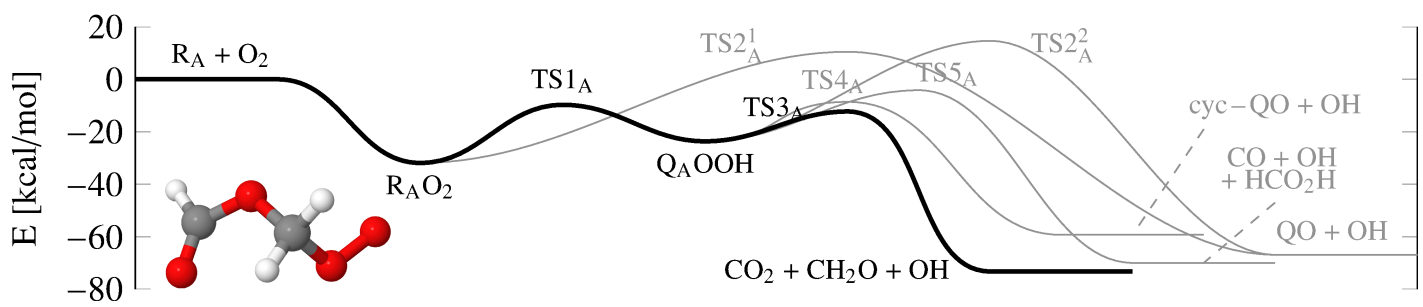

Figure 1: $\mathrm{RO}_{2} / \mathrm{QOOH}$ potential energy surface originating from the methyl-centered MF radical $\left(R_{A}\right)$.

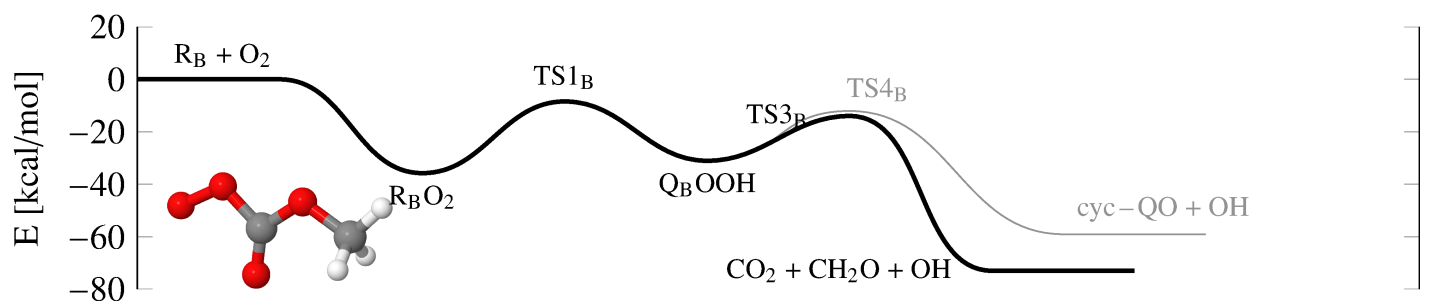

Figure 2: $\mathrm{RO}_{2} / \mathrm{QOOH}$ potential energy surface originating from the formate-centered MF radical $\left(\mathrm{R}_{\mathrm{B}}\right)$.

For both MF radicals the PESs suggest that the major pathway proceeds via $\mathrm{RO}_{2}, \mathrm{QOOH}$, and leads to strongly exothermic dissociation to 
$\mathrm{CO}_{2}, \mathrm{CH}_{2} \mathrm{O}$, and $\mathrm{OH}$ radicals. At combustion-relevant temperatures, however, dissociation to $\mathrm{CO}, \mathrm{OH}$ radicals, and $\mathrm{HCO}_{2} \mathrm{H}$ is entropically favored, as will be shown in the reaction pathway analysis, figure 5. While the initial steps of the PESs are comparable to those of, e.g., dimethyl ether (DME) [35], the QOOH dissociation barrier heights are much lower compared to typical dissociation thresholds [35]. Interestingly, the MF QOOH dissociation thresholds are not only lower than the $\mathrm{R}+\mathrm{O}_{2}$ energy, but also below the $\mathrm{RO}_{2}$ to $\mathrm{QOOH}$ isomerization barrier heights. As a consequence, $\mathrm{QOOH}$ well-skipping is more pronounced for MF than for DME [35], and moreover, $\mathrm{QOOH}$ is prone to dissociation prior to second $\mathrm{O}_{2}$ addition.

Nevertheless, thermalized radical isomerization to $\mathrm{QOOH}$ might become relevant under combustion conditions and especially at elevated pressures. The pronounced $\beta$-scission (thermal and non-thermal), however, consumes most formate-centered MF radicals prior to $\mathrm{O}_{2}$ addition ( $c f$. Figure 4). In conclusion, MF exhibits $\mathrm{RO}_{2}$ chemistry, which is limited to chain propagation and no NTC behavior is expected, as discussed in the following.

\section{Results and discussion}

Figure 3 shows the ignition delay times measured in shock tube and RCM in this study against the results from kinetic simulations. For comparison, predictions using a literature model developed by Dooley et al. [9] and the new model developed here are presented. RCM simulations were performed using effective volume profiles deduced from non-reactive experiments as described in detail by Sung and Curran [42]. The corresponding input files can be found in the Supplementary Material. For the shock tube a constant 


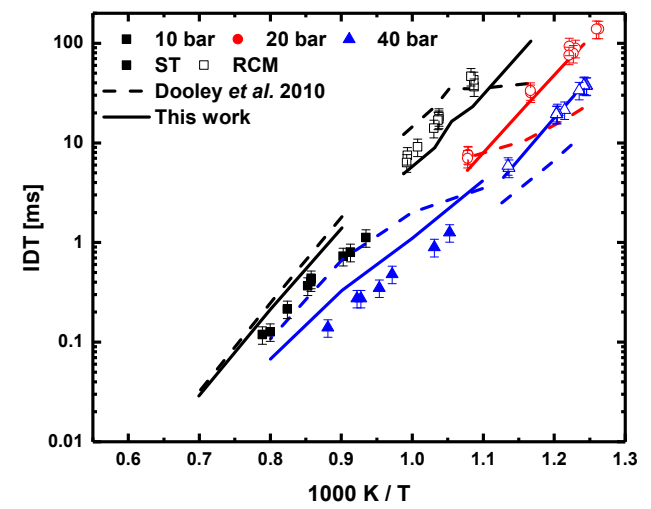

Figure 3: Experimental and predicted ignition delay times of methylformate. Constant volume simulations for shock tube experiments and RCM simulations for RCM experiments

volume reactor was assumed. Experiments were performed at 10, 20 and 40 bar at an equivalence ratio of $\Phi=1.0$. Experiments show an Arrhenius type behavior at high temperatures as previously shown in Ref. [9]. Measurements at lower temperatures in the RCM show similar behavior but a higher pressure dependency.

The kinetic simulations using the mechanism of Dooley et al. also shows Arrhenius type behavior at high temperatures but a change in reactivity at low temperatures. This leads to a significant underprediction of the ignition delay in the low temperature regime at which this mechanism hasn't been validated. Furthermore, the pressure dependency observed at high temperatures is stronger in the experiment than predicted by the mechanism from Dooley et al. [9].

The kinetic model developed in this study reflects the experimentally observed behavior better. On the one hand it is capable to predict the low 


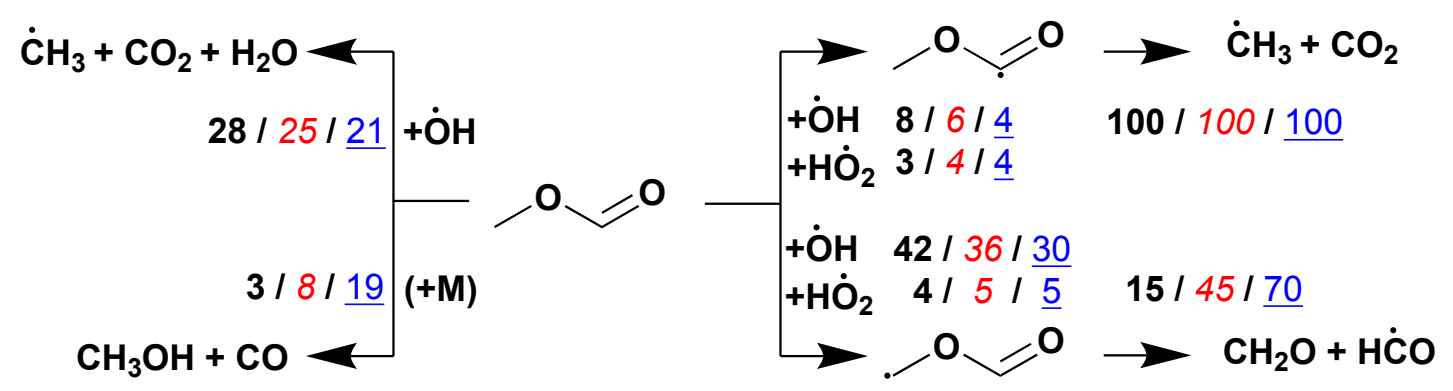

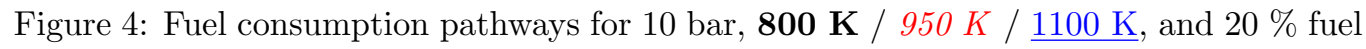
consumption (values in percent)

temperature ignition delay times obtained in the RCM and it also shows a high pressure dependency at higher temperatures similar to the experiments. However, without modifying the ab-initio derived reaction rate coefficients for sensitive reactions the new model overpredicts the ignition delay times by a factor of 2 in this regime. Further comparison against experimental data available in literature are provided in the Supplemental Material showing an overall good agreement of the new model against the high temperature ignition delay time data in diluted mixtures $[9,43]$ and flame speciation data [9]. Ignition delay times for non-diluted experiments at 10 bar [43] are overpredicted similar to the results shown in Fig. 3. The simulations of the high pressure flow reactor show similar deviation from experimental data as discussed in the original paper [15].

In order to provide more insight in the oxidation chemistry of methylformate a flow path analysis has been carried out for stoichiometric fuel-air mixtures at 10 bar, for three different temperatures of $800 \mathrm{~K}, 950 \mathrm{~K}$, and $1100 \mathrm{~K}$ at the time where $20 \%$ of the fuel has been consumed. Fuel consumption reactions (Fig. 4) are dominated by H-atom abstraction on the 


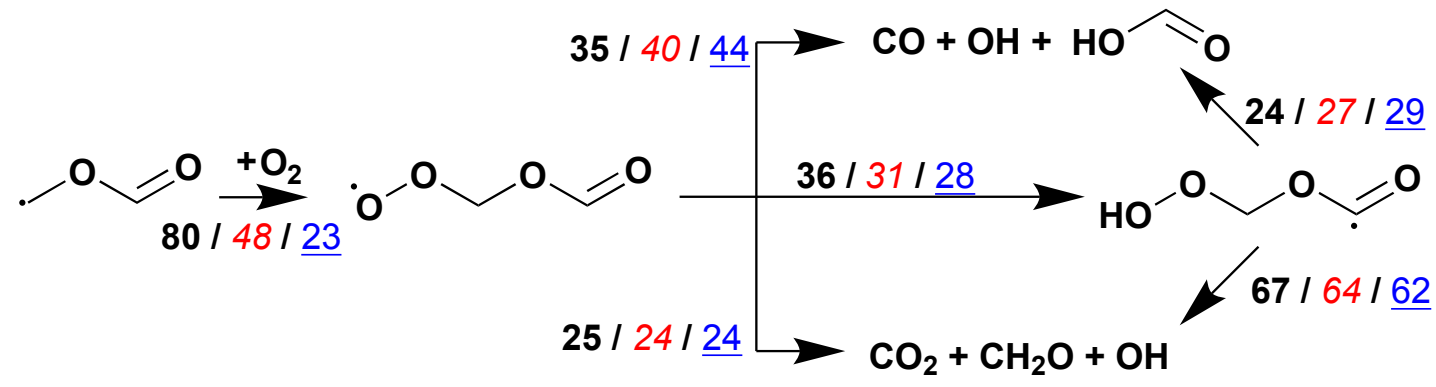

Figure 5: Reaction pathways of the alkyperoxide $\left(\mathrm{RO}_{2}\right)$ for 10 bar, $800 \mathbf{~ K} / 950 \mathrm{~K} /$ $\underline{1100 \mathrm{~K}}$, and $20 \%$ fuel consumption (values in percent)

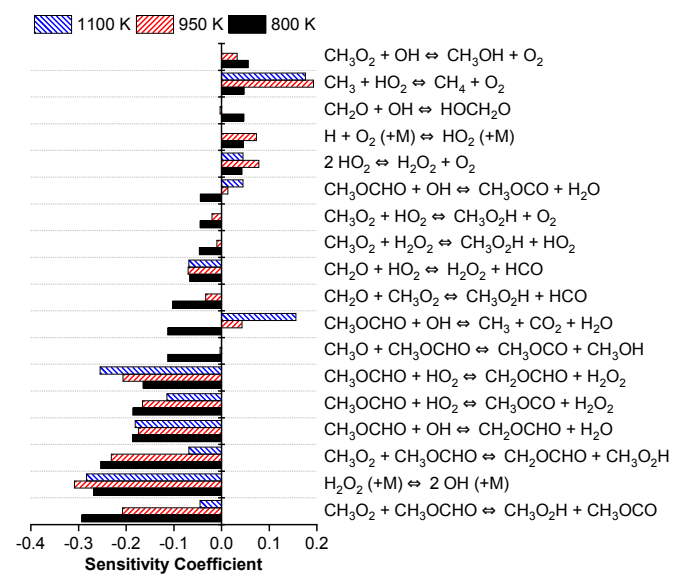

Figure 6: Sensitivity analysis at 10 bar, $\Phi=1.0$ in air

methyl site by $\mathrm{OH}$ at all temperatures. Second most important is the Hatom abstraction by the $\mathrm{OH}$ on the formate site which shows a dominating hot $\beta$-scission pathway towards methyl, $\mathrm{CO}_{2}$ and $\mathrm{H}_{2} \mathrm{O}$ while the thermalization towards the fuel radical is less important. However, as mentioned before further reaction of the thermalized fuel radical with $\mathrm{O}_{2}$ towards the alkylperoxide $\left(\mathrm{RO}_{2}\right)$ is not occurring to significant amounts due to the low stability of $\mathrm{RO}_{2}$ in this case. Consequently the thermalized fuel radical is almost exclusively consumed by the $\beta$-scission reaction towards methyl and $\mathrm{CO}_{2}$. The 
missing alternative reactions lead to the fact that neglecting the possibility of hot $\beta$-scission and instead forcing a complete thermalization of the fuel radical does not lead to different predictions of the model in regards to the ignition delay times since the rate limiting reaction for this pathway is the $\mathrm{H}$-atom abstraction and not the following $\beta$-scission. Finally, unimolecular fuel decomposition becomes relevant at high temperatures.

In contrast to the formate site $\mathrm{O}_{2}$ addition to the fuel radical is possible on the methyl site. In fact, it is the dominating reaction pathway at low temperatures (Fig. 5). Subsequently, approximately $2 / 3$ of the alkyperoxide decompose to a $\mathrm{OH}$ and either $\mathrm{CO}$ and formic acid or $\mathrm{CO}_{2}$ and formaldehyde. Apart from decomposition the majority of the alkylperoxide undergoes internal isomerization towards the alkylhydroperoxyl radical (QOOH). As discussed before, $\mathrm{O}_{2}$ addition on the formate site would lead to a very unstable species so that the majority of the $\mathrm{QOOH}$ is consumed via decomposition pathways. In sum, low-temperature chain branching pathways resulting in the formation of two $\mathrm{OH}$ radicals from the ketohydroperoxide formation and subsequent decomposition as they are typical for alkanes are not occurring for methylformate. Therefore, in agreement to the previous discussion on the PESs no negative temperature coefficient (NTC) behavior is observed in the ignition delay time measurements.

Furthermore, a noticeable formyl radical (HCO) formation is recognizeable mainly initiated through fuel consumption on the methyl site and the subsequent reaction pathways as well as by H-atom abstraction from formaldehyde. The majority of HCO decomposes in the molecular reaction with oxygen towards the hydroperoxyl radical and $\mathrm{CO}$ at all temperatures. Therefore, 
$\mathrm{HCO}$ formation and depletion pathways affect predictions reflecting formation of formaldehyde or CO directely, which numerical results are deviating from the experimental data of Marrodan et al. [15] for both, CO and formaldehyde. Although not sensitive in the IDT simulations, the uncertainty in the estimations for the reaction rate constants of $\mathrm{MF}+\mathrm{HCO}$ might give a reason for these deviations.

In order to identify the root cause for the deviation of the kinetic predictions from the experimental data sensitivity analysis can help identifying reactivity controlling reactions. Accordingly, Fig. 6 depicts a brute-force sensitivity analysis [44] for a stoichiometric fuel in air mixture at 10 bar and at three different temperatures.

Apart from the typical base chemistry reactions H-atom abstraction by various radicals are the most sensitive reactions. At low temperatures H-atom abstraction by $\mathrm{CH}_{3} \mathrm{O}_{2}$ are most sensitive but not so much at high temperatures. $\mathrm{H}$-atom abstractions by $\mathrm{OH}$ and $\mathrm{HO}_{2}$ are sensitive at all temperatures and promoting reactivity except the $\mathrm{H}$-atom abstraction by $\mathrm{OH}$ leading to hot $\beta$-scission. This pathway inhibits reactivity at high temperatures and enhances reactivity at low temperatures. With the aim of optimizing the kinetic model in order to replicate experimental data also at high temperatures sensitive reactions might be modified. However, significant modifications of several rates in the order of factor 4-5 would be necessary to achieve this goal but most of the rate coefficients for the $\mathrm{H}$-atom abstraction reactions have been calculated before with the help of quantum mechanical calculations $[10,11,20]$. Consequently a significant modification of these rates without further detailed investigation would not be reasonable. However, 
$\mathrm{H}$-atom abstraction by $\mathrm{CH}_{3} \mathrm{O}_{2}$ and $\mathrm{CH}_{3} \mathrm{O}$ are still estimated on the basis of analogies and might be uncertain to a significant amount. Furthermore, unimolecular MF decomposition reactions might be significantly underestimated and consequently also not showing up as important reaction in the sensitivity analysis.

\section{Summary and Conclusions}

Experimental IDT of MF were measured in a shock tube and a RCM over temperatures from $790 \mathrm{~K}-1250 \mathrm{~K}$ at high pressures (10, 20, 40 bar) for stoichiometric fuel in air mixtures. A predominantly low- and high-temperature $a b$-initio based detailed kinetic model with incorporated hot $\beta$-scission pathways was developed and compared to these results and the results of a sophisticated model taken from literature [9]. The measured IDT show Arrhenius type behaviour in both facilities over all investigated conditions. The simulations with the model presented in this study reflects the RCM IDT well whereas it overpredicts the IDT at high temperatures by a factor of 2 . Hot $\beta$-scission pathways are dominant at the formate group radical formation although it does not lead to a change in the overall reactivity of methyl formate combustion. This may be reasoned in the lack of thermodynamically driven $\mathrm{RO}_{2}$ formation at the formate radical position. However, even when hot $\beta$-scissions do not show a strong effect on MF combustion it might have a major impact on fuel reactivity when $\mathrm{RO}_{2}$ formation is stable and the fuel tends to undergo hot $\beta$-scission at this abstraction site. Furthermore, for a full understanding of the high-temperature chemistry and for improving

the MF model predictions more ab-initio studies on MF decomposition and 
H-atom abstraction via $\mathrm{CH}_{3} \mathrm{O}, \mathrm{CH}_{3} \mathrm{O}_{2}$ and $\mathrm{HCO}$ are probably needed.

\section{Acknowledgements}

The authors would like to thank Philipp Morsch for his valuable support and the AICES Graduate school of RWTH Aachen University for partially

funding this study. Part of this work was performed as part of the Cluster of Excellence "Tailor-Made Fuels from Biomass" (EXC 236), which is funded by the Excellence Initiative by the German federal and state governments to promote science and research at German universities.

\section{Supplemental Material}

- Literature validation targets (pdf)

- Measured ignition delay times (txt)

- RCM effective volume profiles (zip)

- Detailed kinetic model and species glossary (zip)

\section{References}

[1] M. S. Graboski, R. L. McCormick, Prog. Energy Combust. Sci. 24 (1998) $125-164$.

[2] I. Liu, N. W. Cant, J. H. Bromly, P. F. Nelson, B. S. Haynes, Chemosphere 42 (2001) 583-589.

[3] C. A. Daly, J. M. Simmie, P. Dagaut, M. Cathonnet, Combust. Flame 125 (2001) 1106-1117. 
[4] W. A. Kopp, L. C. Kröger, M. Döntgen, S. Jacobs, U. Burke, H. J. Curran, K. A. Heufer, K. Leonhard, Combust. Flame (2017).

[5] S. E. Iannuzzi, C. Barro, K. Baulouchos, J. Burger, Fuel 167 (2016) 49-59.

[6] J. Burger, M. Siegert, E. Stroefer, H. Hasse, Fuel 89 (2010) 3315-3319.

[7] M. Döntgen, L. C. Kröger, K. Leonhard, Proc. Combust. Inst. 36 (2017) $135-142$.

[8] M. Döntgen, K. Leonhard, J. Phys. Chem. A 121 (2017) 1563-1570.

[9] S. Dooley, M. P. Burke, M. Chaos, Y. Stein, F. L. Dryer, V. P. Zhukov, O. Finch, J. M. Simmie, H. J. Curran, Int. J. Chem. Kinet. 42 (2010) $527-549$.

[10] T. Tan, M. Pavone, D. B. Krisiloff, E. A. Carter, J. Phys. Chem. A 116 (2012) 8431-8443.

[11] T. Tan, M. Pavone, D. B. Krisiloff, E. A. Carter, J. Phys. Chem. A 119 (2015) 2186-2186.

[12] R. H. West, C. F. Goldsmith, M. R. Harper, G. W. H., L. Catoire, N. Chaumeix, in: 7th National Technical Meeting of the Combutsion Institute (2011).

[13] C. W. Gao, J. W. Allen, W. H. Green, R. H. West, Comput. Phys. Commun. 203 (2016) 212-225. 
[14] M. U. Alzueta, V. Aranda, F. Monge, A. Millera, R. Bilbao, Combust. Flame 160 (2013) 853-860.

[15] L. Marrodán, A. Millera, R. Bilbao, M. U. Alzueta, Energy Fuels 28 (2014) 6107-6115.

[16] W. K. Metcalfe, J. M. Simmie, H. J. Curran, J. Phys. Chem. A 114 (2010) 5478-5484. PMID: 20380414.

[17] J. S. Francisco, J. Am. Chem. Soc. 125 (2003) 10475-10480.

[18] W. Ren, K.-Y. Lam, S. Pyun, A. Farooq, D. Davidson, R. Hanson, Proc. Combust. Inst. 34 (2013) $453-461$.

[19] W. Ren, E. Dames, D. Hyland, D. F. Davidson, R. K. Hanson, Combust. Flame 160 (2013) 2669 - 2679.

[20] T. Tan, X. Yang, Y. Ju, E. A. Carter, J. Phys. Chem. B 120 (2016) $1590-6000$.

[21] M. P. Burke, C. F. Goldsmith, Y. Georgievskii, S. J. Klippenstein, Proc. Combust. Inst. 35 (2015) $205-213$.

[22] C. F. Goldsmith, M. P. Burke, Y. Georgievskii, S. J. Klippenstein, Proc. Combust. Inst. 35 (2015) $283-290$.

[23] N. J. Labbe, R. Sivaramakrishnan, C. F. Goldsmith, Y. Georgievskii, J. A. Miller, S. J. Klippenstein, J. Phys. Chem. Lett. 7 (2016) 85-89. 
[24] N. J. Labbe, R. Sivaramakrishnan, C. F. Goldsmith, Y. Georgievskii, J. A. Miller, S. J. Klippenstein, Proc. Combust. Inst. 36 (2017) 525 532.

[25] C. Lee, S. Vranckx, K. A. Heufer, S. V. Khomik, Y. Uygun, H. Olivier, R. X. Fernandes, Z. Phys. Chem. 226 (2012) 1-27.

[26] C. Morley, Gaseq, http://www.gaseq.co.uk/, 2005. Accessed: 2017$11-15$.

[27] A. Ramalingam, K. Zhang, A. Dhongde, L. Virnich, H. Sankhla, H. Curran, A. Heufer, Fuel 206 (2017) 325 - 333.

[28] K. Zhang, C. Banyon, J. Bugler, H. J. Curran, A. Rodriguez, O. Herbinet, F. Battin-Leclerc, C. B'Chir, K. A. Heufer, Combust. Flame 172 (2016) $116-135$.

[29] H. Minwegen, U. Burke, K. A. Heufer, Proc. Combust. Inst. 36 (2017) $561-568$.

[30] D. G. Goodwin, H. K. Moffat, R. L. Speth, Cantera: An object-oriented software toolkit for chemical kinetics, thermodynamics, and transport processes, http://www . cantera.org, 2015. Version 2.2.0.

[31] Shock and detonation toolbox, http://shepherd.caltech.edu/EDL/ public/cantera/html/SD_Toolbox/, 2014. Accessed: 2015-11-25.

[32] S. M. Burke, U. Burke, R. McDonagh, et al., Combust. Flame 162 (2015) $296-314$. 
[33] B. I. Parsons, C. J. Hinshelwood, J. Chem. Soc. 0 (1956) 1799-1703.

[34] E. Fisher, W. Pitz, H. Curran, C. Westbrook, Proc. Combust. Inst. 28 (2000) $1579-1586$.

[35] A. J. Eskola, S. A. Carr, R. J. Shannon, M. A. Blitz, M. J. Pilling, P. W. Seakins, S. H. Robertson, J. Phys. Chem. C 118 (2014) 6773-6788.

[36] Frisch, et al., Guassian 09, revision a.02, 2016.

[37] K. Bak, A. Halkier, P. Jrgensen, J. Olsen, T. Helgaker, W. Klopper, J. Mol. Struct 567-568 (2001) 375 - 384 .

[38] Y. Georgievskii, J. A. Miller, M. p. Burke, S. J. Klippenstein, J. Phys. Chem. A 117 (2013) 12146-12154.

[39] M. Döntgen, J. L. Beeckmann, K. O. Leonhard, H. G. Pitsch, S. J. Klippenstein, in: 7th European Combustion Meeting (2015). http:// www . ecm2015.hu/papers/P1-12.pdf.

[40] H.-H. Carstensen, A. M. Dean, Comprehensive Chemical Kinetics 42 (2007) 101-184.

[41] Y. Li, C.-W. Zhou, K. P. Somers, K. Zhang, H. J. Curran, Proc. Combust. Inst. 36 (2017) $403-411$.

[42] C.-J. Sung, H. J. Curran, Prog. Energy Combust. Sci. 44 (2014) 1 - 18.

[43] B. Akih-Kumgeh, J. M. Bergthorson, Energy Fuels 24 (2010) 396-403. 
[44] U. Burke, K. P. Somers, P. O'Toole, C. M. Zinner, N. Marquet, G. Bourque, E. L. Peterson, W. K. Metcalfe, Z. Serinyel, H. J. Curran, Combust. Flame 162 (2015) 315-330. 